\title{
Neurotensin Receptor Antagonist SR 142948A Alters Fos Expression and Extrapyramidal Side Effect Profile of Typical and Atypical Antipsychotic Drugs
}

\author{
Elisabeth B Binder ${ }^{1,2}$, Becky Kinkead', Michael J Owens' and Charles B Nemeroff*,' \\ 'Laboratory of Neuropsychopharmacology, Department of Psychiatry and Behavioral Sciences, Emory University School of Medicine, Atlanta, \\ GA, USA
}

\begin{abstract}
Antipsychotic drugs (APDs) have previously been shown to alter Fos expression in a regionally specific manner. Increases in Fos expression in the nucleus accumbens (NAcc) are common to all clinically effective APDs. In contrast, APD-induced Fos expression increases in the caudate-putamen (CPu) and prefrontal cortex (PFC) are associated with the extrapyramidal side effect liability of typical APDs or the effectiveness against negative symptoms of atypical APDs, respectively. Considerable evidence suggests that the neuropeptide neurotensin (NT) mediates some of the effects of APDs. To determine whether NT neurotransmission is also involved in APD-induced Fos expression in brain regions relevant for therapeutic efficacy, the NT receptor antagonist SR I42948A (I0 or I00 $\mu$ g/ kg i.p.) was coadministered with APDs (haloperidol ( $2.0 \mathrm{mg} / \mathrm{kg}$ s.c.), olanzapine (5 mg/kg i.p.), or clozapine (20 mg/kg s.c.)). Fos expression was evaluated in the PFC, NAcc shell, dorsomedial, and dorsolateral CPu and the lateral septum. SR I42948A attenuated haloperidolinduced Fos expression in the CPu but, in contrast, increased olanzapine-induced Fos expression in this brain region. The effects of the NT receptor antagonist were paralleled by its effects on catalepsy in olanzapine - but not haloperidol — treated animals. Neuropsychopharmacology (2004) 29, 2200-2207, advance online publication, 25 August 2004; doi: I 0. I038/sj.npp. I 300546
\end{abstract}

Keywords: neurotensin; SR I42948A; antipsychotic drugs; catalepsy; immediate early gene

\section{INTRODUCTION}

Schizophrenia is a devastating psychiatric disease with a worldwide prevalence of approximately $1 \%$. Antipsychotic drugs (APDs) have repeatedly been shown to be effective in reducing many of the cardinal symptoms of schizophrenia, and yet the underlying neurochemical actions responsible for their clinical efficacy remain poorly understood. Mapping of specific APD-induced changes in immediate early gene expression has been used to identify brain regions and neurotransmitter systems involved in mediating the action of APDs. To date, all clinically effective APDs increase the expression of the immediate early gene Fos in the nucleus accumbens (NAcc) shell (Deutch et al, 1992; Fibiger, 1994; Robertson and Fibiger, 1992). Increased Fos

*Correspondence: Dr CB Nemeroff, Department of Psychiatry and Behavioral Sciences, Emory University School of Medicine, Suite 4000 WMRB, 1639 Pierce Dr, Atlanta, GA 30322, USA, Tel + I 404727 8382, Fax + I 404727 3233, E-mail: cnemero@emory.edu

${ }^{2}$ Current address: Max-Planck Institute of Psychiatry, Kraepelinstr. 10, 80804 Munich, Germany.

Received 14 September 2003; revised 22 June 2004; accepted 20 July 2004

Online publication: 27 July 2004 at http://www.acnp.org/citations/ Npp07270403420/default.pdf expression in this brain region is thus considered to be predictive of antipsychotic activity. In contrast, only typical (eg haloperidol) but not atypical (eg clozapine and olanzapine) APDs increase Fos in the dorsolateral caudate/putamen ( $\mathrm{CPu}$ ) (Deutch et al, 1992; Fibiger, 1994; Robertson and Fibiger, 1992), and this has been attributed to the typical APD propensity for eliciting extrapyramidal side effects (EPSEs). Additionally, atypical APDs with purported superior efficacy against negative symptoms of schizophrenia (eg amotivation and anhedonia) increase Fos in the medial prefrontal cortex (PFC), specifically in the deep layers of the infralimbic and ventral prelimbic cortices (Deutch, 1994; Fibiger, 1994; Merchant et al, 1996; Robertson and Fibiger, 1996). APDs have also been reported to increase Fos expression in other, mostly limbic brain regions, with increases in the lateral septum being the most consistent finding (Cohen and Wan, 1996; Deutch et al, 1995; Sebens et al, 1995). Manipulating APD-induced Fos expression could therefore serve as an indicator as to which neurotransmitter pathways are involved in the specific effects of APDs.

A concatenation of data points to the fact that the tridecapeptide neurotensin (NT) may be involved in the therapeutic efficacy and side effect profile of APDs (Binder et al, 2001b; Kinkead et al, 1999). Typical and atypical APDs 
increase NT/Neuromedin N (NT/NN) mRNA expression, NT tissue concentrations and NT release in the NAcc, an effect seen following both acute and chronic drug administration (Huang and Hanson, 1997; Kilts et al, 1988; Kinkead et al, 2000; Merchant et al, 1992; Radke et al, 1989, 1998). Only typical APDs increase NT/NN mRNA expression, NT tissue concentrations and NT release in the $\mathrm{CPu}$. There is therefore a striking overlap between APD-induced Fos expression and APD-induced NT release. Moreover, NT receptor activation has been shown to induce Fos expression both in vivo and in vitro (Ehlers et al, 1998; Lambert et al, 1996; Portier et al, 1998).

Increased NT neurotransmission following APD administration may therefore contribute to some extent to the observed APD-induced increases in Fos expression and by extension the therapeutic efficacy and side effect profile of these drugs. Two recent studies have confirmed that NT neurotransmission partly mediates haloperidol-induced Fos expression in the $\mathrm{CPu}$, but not in the NAcc (Fadel et al, 2001; Dobner et al, 2001). This was shown using the NT receptor antagonist SR 48692 and transgenic mice lacking a functional NT/NN gene, respectively. Interestingly, even though NT-deficient mice showed an attenuated Fos response to haloperidol, the catalepsy-inducing effects of the drug remained unchanged in these animals.

In the following set of experiments we addressed two main questions. First, is NT neurotransmission involved in the induction of Fos-expression in limbic brain regions (NAcc, PFC, LS) thought to be associated with the therapeutic efficacy of APDs? Our group has shown that NT-neurotransmission mediates the effects of typical as well as atypical APDs on sensorimotor gating in rats (Binder et al, 2001a). It has been proposed that the restoration of pre-existing deficits in sensorimotor gating in schizophrenic patients may be an important factor for the therapeutic efficacy of these drugs (Braff and Geyer, 1990; Swerdlow and Geyer, 1998). The assessment of changes in APD-induced Fos-expression following administration of the NT receptor antagonist may help to identify which brain regions are involved in these behavioral effects. To test whether NT neurotransmission is involved in the induction of Fosexpression in limbic brain regions, we examined the effects of the NT receptor antagonist SR 142948A at two dose levels on Fos expression induced by typical (haloperidol) and atypical (clozapine and olanzapine) APDs in the dorsomedial and dorsolateral $\mathrm{CPu}$, NAcc shell, PFC, and LS.

Second, does the dissociation of APD-induced Fos expression and catalepsy observed in transgenic mice lacking the NT/NN gene (Dobner et al, 2001) reflect the physiology in intact animals or is it due to developmental adaptations in NT/NN knockout mice? To that aim, we examined the effect of the NT receptor antagonist SR 142948A on haloperidol-induced catalepsy and on cataleptic behavior in clozapine and olanzapine-treated rats, at doses that do not induce catalepsy by themselves.

\section{METHODS}

\section{Animals and Housing}

Adult male Sprague-Dawley rats (300-400 g, Charles River Laboratories, Raleigh, NC) were housed three per cage on reverse dark-light cycle (lights on 2200, lights off 1000). Food and water were available ad libidum. All animal protocols were approved be The Emory University Institutional Animal Care and Use Committee in accordance with the Guide for the Care and Use of Laboratory Animals as adopted and promulgated by the National Institutes of Health.

\section{Drug Administration}

The NT receptor antagonist SR 142948A (2-[[5-(2,6dimethoxyphenyl)-1-(4-(N-(3-dimethylaminopropyl)- $N$ methylcarbamoyl)-2-isopropylphenyl)-1H-pyrazole3-carbonyl]amino] adamantane-2-carboxylic acid, hydrochloride) was a generous gift of Sanofi Recherche (Toulouse, France). SR 142948A was suspended in several drops of Tween 20 and brought to volume with $0.9 \% \mathrm{NaCl}$ (drug vehicle $=0.9 \%$ $\mathrm{NaCl}$ plus several drops of Tween 20). Haloperidol (Sigma Chemical Co., St Louis, MO) was dissolved in $0.3 \%$ tartaric acid (drug vehicle), clozapine (Sandoz Pharmaceuticals) and olanzapine (Eli Lilly Co.) in $0.3 \%$ tartaric acid with a few drops of glacial acetic acid (drug vehicle). All drugs were administered in a fixed volume of $1.0 \mathrm{ml} / \mathrm{kg}$ body weight. Haloperidol and clozapine were administered subcutaneously (s.c.) and SR 142948A and olanzapine were administered intraperitoneally (i.p.).

\section{Immunohistochemistry-Drug Administration and Brain Preparation}

Drug treatments were all conducted in the dark phase between $1100-1600$ on six experimental days. Each treatment group consisted of 13-15 animals. SR 142948A (10 and $100 \mu \mathrm{g} / \mathrm{kg}$ ) or its vehicle was administered $1 \mathrm{~h}$ before the administration of haloperidol $(2.0 \mathrm{mg} / \mathrm{kg}$ s.c. $)$, olanzapine ( $5 \mathrm{mg} / \mathrm{kg}$ i.p.), clozapine $(20 \mathrm{mg} / \mathrm{kg}$ s.c.), or their respective vehicles. At $2 \mathrm{~h}$ after APD administration animals used for Fos immunohistochemistry were deeply anesthetized with Euthanasia 5 solution (E. Schein Inc., Port Washington, NY, $1.0 \mathrm{ml} / \mathrm{kg}$ ) and immediately perfused transcardially at $4{ }^{\circ} \mathrm{C}$ with saline followed by $4 \%$ paraformaldehyde in $0.1 \mathrm{M}$ sodium phosphate buffer ( $\mathrm{pH}$ 7.6). Each brain was removed immediately after perfusion and placed in fresh $4 \%$ paraformaldehyde for $24 \mathrm{~h}$ at $4{ }^{\circ} \mathrm{C}$ on a rotating shaker. Brains were then switched to a $20 \%$ sucrose solution in $0.1 \mathrm{M}$ sodium phosphate buffer and left on the rotating shaker at $4{ }^{\circ} \mathrm{C}$ for another $48 \mathrm{~h}$. Brains were then rinsed, patted dry, frozen and kept at $-70^{\circ} \mathrm{C}$ until further use.

\section{Fos Immunohistochemistry}

Brains were sectioned coronally at $35 \mu \mathrm{m}$ on a freezing microtome and slices were collected into cryoprotectant solution $(50 \% \quad 0.05 \mathrm{M}$ sodium phosphate buffer, $30 \%$ ethylene glycol, $20 \%$ glycerol) and stored at $-20^{\circ} \mathrm{C}$ until use. All steps of the immunohistochemistry were carried out on a rotating shaker table. Brain slices were rinsed $(4 \times 15 \mathrm{~min})$ in $0.05 \mathrm{M}$ potassium phosphate-buffered saline (KPBS), pH 7.2 and then incubated for $20 \mathrm{~min}$ in methanol containing $1 \%$ hydrogen peroxide to block endogenous peroxidase activity. Brain sections were then transferred into KPBS containing $4 \%$ normal goat serum, $1 \%$ bovine 
serum albumin (BSA) and $0.4 \%$ Triton X-100 and incubated for $1 \mathrm{~h}$. Sections were subsequently incubated at $4{ }^{\circ} \mathrm{C}$ for $72 \mathrm{~h}$ with the primary rabbit Fos antibody (Oncogene Research Products) diluted to $1: 20000$ in KPBS containing $1 \%$ normal goat serum, $1 \%$ BSA, and $0.4 \%$ Triton $\mathrm{X}-100$. This rabbit polyclonal Fos antiserum was raised against residues 4-17 of human Fos and recognizes c-fos but not Fos-related antigens. Sections were then rinsed $(5 \times 15 \mathrm{~min})$ in KPBS containing $0.02 \%$ Triton X-100 and $0.25 \%$ BSA, and incubated with a biotinylated goat-antirabbit secondary antiserum (1:1000 dilution, Vector Laboratories) for $90 \mathrm{~min}$ in KPBS containing $0.02 \%$ Triton X-100 and $1 \%$ BSA. Brain slices were then washed with KPBS containing $0.25 \%$ BSA and incubated for 90 min in KPBS containing $1 \%$ BSA and $0.25 \%$ of the avidin-biotinylated horseradish peroxidase (Vectastain AbC Elite Kit, Vector Laboratories). Sections were then rinsed in KPBS $(2 \times 10 \mathrm{~min})$ and $0.175 \mathrm{M}$ sodium acetate, $\mathrm{pH} 7.2(2 \times 10 \mathrm{~min})$. The peroxidase conjugated antibody was visualized using a nickel (II) sulfate intensification of the chromagen 3,3-diaminobenzidine tetrachloride (DAB) staining. Sections were then washed in $0.175 \mathrm{M}$ sodium acetate $(10 \mathrm{~min})$ and KPBS $(10 \mathrm{~min})$ and mounted on Superfrost ${ }^{\mathrm{TM}}$-plus coated slides, dried for $48 \mathrm{~h}$, counterstained with methyl-green, and coverslipped with $\mathrm{DPX}^{\mathrm{TM}}$ mountant.

\section{Counting of Labeled Cells and Data Analysis}

The number of Fos-like immunoreactive neurons in the prelimbic/infralimbic cortex, NAcc shell, dorsomedial and dorsolateral $\mathrm{CPu}$, and lateral septum (according to the Paxinos and Watson, 1986) in both hemispheres was determined using an image analysis system equipped with Image 1.60 software (developed at the US National Institutes of Health and available on the internet at: http://rsb.info. nih.gov/nih-image) (see Figure 1). Due to tissue loss during brain preparation, the effective $n$ per group/per brain region varies by up to three animals, leaving an $n$ of 10-13 animals per group. An image was relayed from a light microscope $(100 \times$ magnification) to a computer screen. Once digitized, the contrast was set such that only cell nuclei identified by the observer as Fos-positive in the microscope were counted as positive. Constant density threshold and target acceptance criteria were used to quantify Fos-positive neurons. For all brain regions, Fos-positive neurons were counted in one or two distinct $600 \times 400 \mu \mathrm{m}^{2}$ areas in each hemisphere (see Figure 1). The number of Fos-positive neurons is expressed as the average number of positive neurons $/ \mathrm{mm}^{2}$.

\section{Catalepsy}

Catalepsy was measured using the wood block test as well as the bar test in two separate sets of male Sprague-Dawley rats. Rats ( $n=6-7 /$ group for the wood block test and 5-10/ group for the bar test) received a single injection of SR $142948 \mathrm{~A}(100 \mu \mathrm{g} / \mathrm{kg}$ i.p. $)$ or vehicle $1 \mathrm{~h}$ before administration of haloperidol (2.0 mg/kg s.c.), olanzapine ( $5.0 \mathrm{mg} / \mathrm{kg}$ i.p.), clozapine $(20.0 \mathrm{mg} / \mathrm{kg}$ s.c.), or vehicle. For the wood block test, a rectangular wooden block of $6 \mathrm{~cm}$ height was used (Ellenbroek et al, 1987). Rats were placed with both forelimbs on the edge of the block and latency to move a

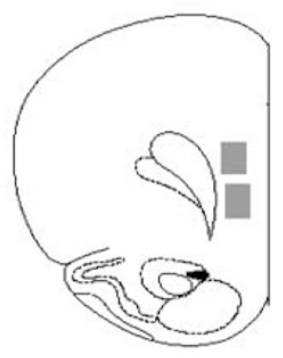

C

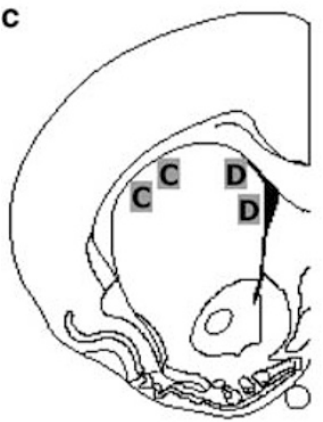

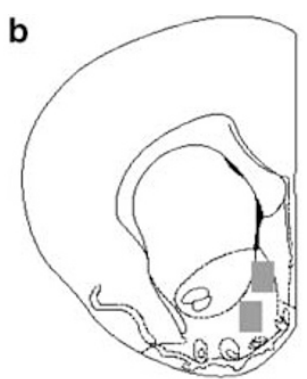

d

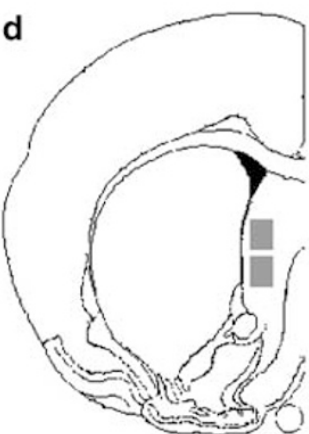

Figure I Brain regions in which Fos-like immunoreactivity was determined (according to Paxinos rat brain atlas). (a) prelimbic/infralimbic cortex $(+3.20 \mathrm{~mm}$ of bregma), (b) nucleus accumbens shell $(+1.70 \mathrm{~mm}$ of bregma), (c) dorsolateral (C) and dorsomedial (D) striatum (+1.00 mm of bregma) and (d) lateral septum ( $+0.20 \mathrm{~mm}$ of bregma).

one foot off the block was measured (descent latency in seconds) 5, 15, 30, and 60 min after administration of the APD or its vehicle. For the bar test, a plastic bar fixed in an animal cage at a height of $6 \mathrm{~cm}$ was used and rats were placed with both forelimbs on the bar. Latency to move one foot off the bar was measured in a similar manner than for the wood block test.

\section{Statistical Analysis}

There were no significant differences among the control animals treated with different vehicles $(0.3 \%$ tartaric acid or $0.3 \%$ tartaric acid with a few drops of glacial acetic acid), so control animals were combined for further analysis. Data were analyzed by two-way analysis of variance (ANOVA) with APD treatment $\times$ SR 142948A dose as factors. To account for possible effects of the experimental day on basal and drug-induced changes in Fos expression, the experimental day was added as covariate in these analyses. The cataleptic effect of a combination of compounds was expressed as the area under the curve for the descent latency values measured at four time points $(5,15,30$, and $60 \mathrm{~min}$ after injection). For olanzapine effects, a one-way ANOVA for each time point (vehicle/vehicle, vehicle/olanzapine, and SR142948A/olanzapine as groups) was used to determine differences in the onset of cataleptic behavior. The Fischer LSD test was used as multiple comparison procedure for post hoc analysis. $p<0.05$ was considered the limit for statistical significance. 


\section{RESULTS}

\section{Effects of SR 142948A on APD-Induced Fos Expression}

Prefrontal cortex. Two-way ANOVA revealed a significant APD treatment effect $\left(\mathrm{F}_{3,323}=50.3, p<0.001\right)$ and of the covariate experimental day $\left(\mathrm{F}_{1,323}=12.2, p=0.001\right)$, but no significant SR 142948A dose effect or interaction between the two factors. Post hoc analysis showed that only clozapine $(p<0.001)$ and olanzapine $(p<0.001)$, but not haloperidol, significantly increased the number of Fos positive neurons in the PFC (Figure 2). The effects of clozapine and olanzapine were not different from each other. The NTR antagonist had no significant effect in vehicle or APD treated animals.

\section{NAcc Shell Subdivision}

Two-way ANOVA revealed a significant APD treatment effect $\left(p<0.001 ; \mathrm{F}_{3,425}=174.2\right)$ and of the covariate experimental day $\left(p<0.001 ; \mathrm{F}_{1,425}=28.4\right)$, but no significant SR $142948 \mathrm{~A}$ dose effect or interaction between the two factors. Post hoc analysis showed that haloperidol, olanzapine, and clozapine significantly $(p<0.001)$ increased the number of Fos positive neurons in the NAcc compared to vehicle (Figure 3). Although olanzapine and clozapine, and clozapine and haloperidol-induced Fos increases were not significantly different from each other, olanzapine had a significantly larger effect than haloperidol $(p=0.01)$. SR $142948 \mathrm{~A}(10$ or $100 \mu \mathrm{g} / \mathrm{kg}$ ) had no significant effect on Fos expression in vehicle, haloperidol, or olanzapine treated animals.

\section{Dorsomedial $\mathrm{CPu}$}

In the dorsomedial $\mathrm{CPu}$, two-way ANOVA revealed a significant effect of APD treatment $\left(p<0.001 ; \mathrm{F}_{3,434}=142.6\right)$,

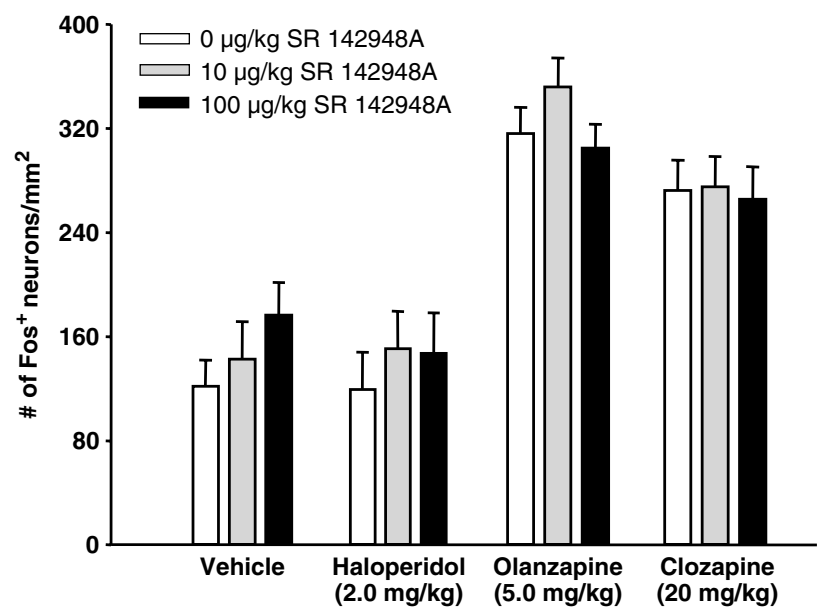

Figure 2 Effects of the neurotensin receptor antagonist SR I42948A on antipsychotic drug-induced Fos expression in the prefrontal cortex. SR I42948A (0, 10, or $100 \mu \mathrm{g} / \mathrm{kg}$ i.p.) was administered I h before administration of antipsychotic drug. Fos-like immunoreactivity was measured $2 \mathrm{~h}$ after antipsychotic drug administration. Olanzapine and clozapine, but not haloperidol, significantly increase Fos expression from the vehicle/vehicle group independent of pretreatment with SR 142948A; $p<0.00$ I for all groups.

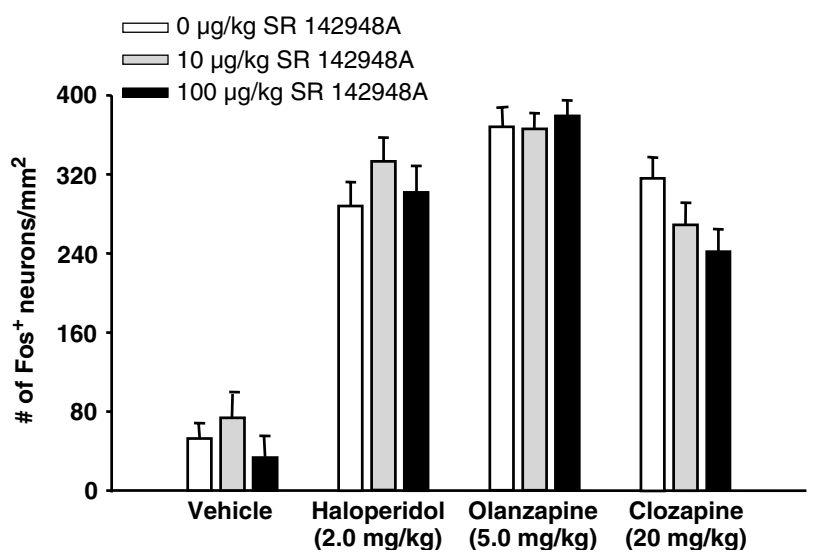

Figure 3 Effects of the neurotensin receptor antagonist SR I42948A on antipsychotic drug-induced Fos expression in the shell of the nucleus accumbens. SR I42948A (0, I0, or $100 \mu g / \mathrm{kg}$ i.p.) was administered I h before administration of antipsychotic drug. Fos-like immunoreactivity was measured $2 \mathrm{~h}$ after antipsychotic drug administration. All three antipsychotic drugs significantly increase Fos expression from the vehicle/ vehicle group independent of pretreatment with SR I42948A; $p<0.00$ I for all groups.

no effect of SR 142948A dose, but a significant interaction between the two factors $\left(p<0.05 ; \mathrm{F}_{6,434}=2.5\right)$ (Figure 4a). There was no significant effect of the covariate experimental day. Post hoc analysis showed that all APDs significantly increased the number of Fos positive neurons in the dorsomedial $\mathrm{CPu}(p<0.001$ for haloperidol and olanzapine and $p<0.005$ for clozapine). Increases in Fos expression following haloperidol were significantly larger than the ones observed with olanzapine and clozapine, $p<0.005$ and $<0.001$ respectively. The effects of olanzapine were also significantly larger $(p<0.001)$ than the effects of clozapine. Pretreatment with the NTR antagonist significantly increased olanzapine-induced Fos expression at both doses (38\% with $p<0.005$ at $10 \mu \mathrm{g} / \mathrm{kg}$ and $57 \%$ with $p<0.001$ at $100 \mu \mathrm{g} / \mathrm{kg}$ of SR 142948A of Fos-positive neurons induced by olanzapine alone). SR 142948A had no significant effects in vehicle, haloperidol, and clozapine treated animals.

\section{Dorsolateral CPu}

Two-way ANOVA revealed a significant APD treatment effect $\left(p<0.001 ; F_{3,429}=159.0\right)$, a significant SR 142948A dose effect $\left(p<0.05 ; \mathrm{F}_{2,429}=3.4\right)$ and a significant interaction between the two factors $\left(p<0.001 ; \mathrm{F}_{6,429}=4.2\right)$ (Figure $4 \mathrm{~b}$ ). There was no significant effect of the covariate experimental day. Post hoc analysis showed that all APDs significantly increased the number of Fos positive neurons in the dorsolateral $\mathrm{CPu} \quad(p<0.001$ for haloperidol and olanzapine and $p<0.05$ for clozapine). Increases in Fos expression following haloperidol, however, were markedly and significantly higher $(p<0.001)$ than the ones observed with the two atypical APDs; $469 \%$ higher than olanzapineand $977 \%$ higher than clozapine-induced increases in Fos expression in this brain region. The effects of olanzapine on Fos expression in this brain region were also significantly higher $(p<0.05)$ than the effects of clozapine. Pretreatment with the NTR antagonist significantly decreased $(p<0.001)$ 

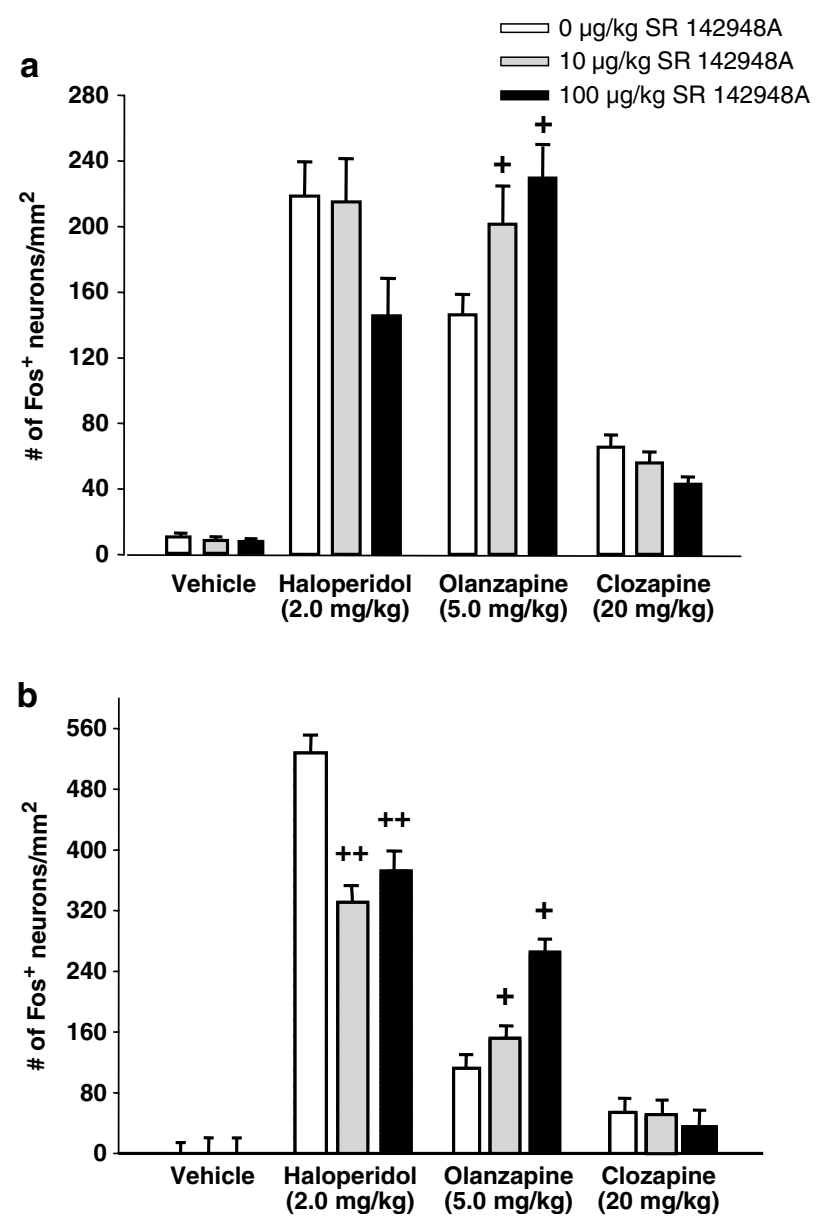

Figure 4 Effects of the neurotensin receptor antagonist SR I42948A on antipsychotic drug-induced Fos expression in the dorsomedial (a) and dorsolateral (b) caudate/putamen. SR I42948A (0, 10, or $100 \mu \mathrm{g} / \mathrm{kg}$ i.p.) was administered I h before administration of antipsychotic drug. Fos-like immunoreactivity was measured $2 \mathrm{~h}$ after antipsychotic drug administration. (a) All three antipsychotic drugs significantly increase Fos expression from the vehicle/vehicle group independent of pretreatment with SR I42948A; $p<0.005$ for all groups. $+p<0.05$ compared to olanzapine alone. (b) Haloperidol and olanzapine significantly increase Fos expression from the vehicle/vehicle group independent of pretreatment with SR I42948A $p<0.00$ I for all groups, for clozapine, only the vehicle/clozapine group is significantly different from vehicle/vehicle; $p<0.05 .++p<0.05 \mathrm{com}-$ pared to vehicle/haloperidol; $+p<0.05$ compared to vehicle/olanzapine.

haloperidol-induced Fos expression by about a third (37\% decrease at $10 \mu \mathrm{g} / \mathrm{kg}$ and $29 \%$ decrease at $100 \mu \mathrm{g} / \mathrm{kg}$ of SR 142948 A). In contrast, SR 142948A significantly increased $(p<0.001)$ olanzapine-induced Fos expression in this brain region. The number of Fos positive neurons was 35 and $135 \%$ higher in animals pretreated with 10 or $100 \mu \mathrm{g} / \mathrm{kg}$ of SR 142948A, respectively, than in animals that received only olanzapine. The NTR antagonist did not significantly affect Fos immunoreactivity in vehicle and clozapine treated animals.

\section{Lateral Septum}

Two-way ANOVA revealed a significant APD treatment effect $\left(p<0.001 ; F_{3,394}=112.2\right)$ and of the covariate experimental day $\left(p<0.001 ; \mathrm{F}_{1,394}=12.5\right)$, but no significant SR

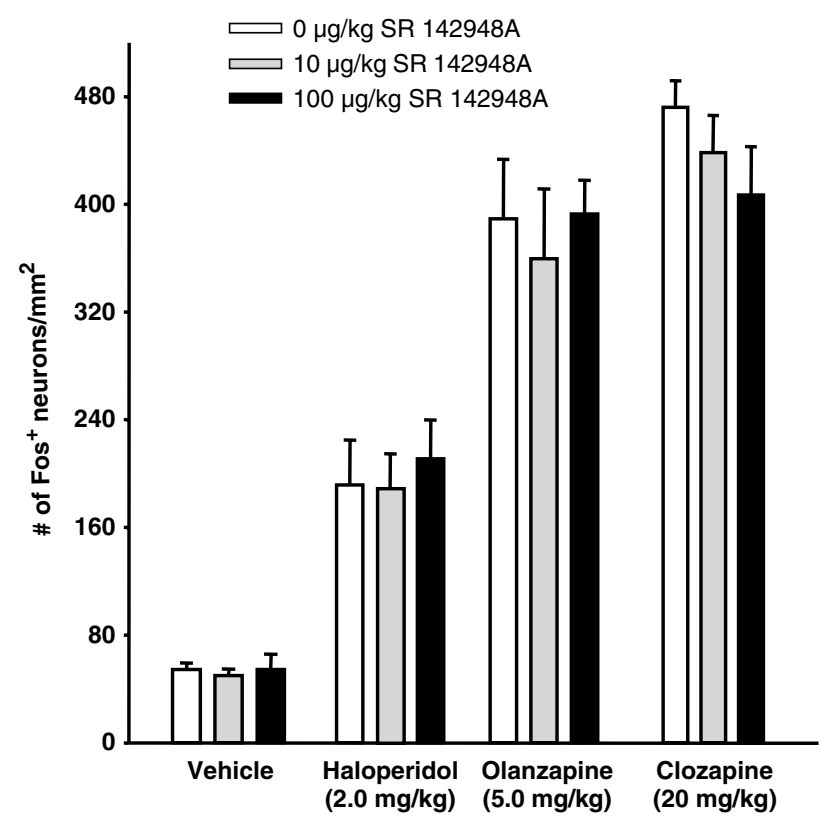

Figure 5 Effects of the neurotensin receptor antagonist SR I42948A on antipsychotic drug-induced Fos expression in the lateral septum. SR I42948A (0, 10, or $100 \mu g / \mathrm{kg}$ i.p.) was administered I h before administration of antipsychotic drug. Fos-like immunoreactivity was measured $2 \mathrm{~h}$ after antipsychotic drug administration. All three antipsychotic drugs significantly increase Fos expression from the vehicle/vehicle group independent of pretreatment with SR I42948A ( $p<0.00$ I for olanzapine and clozapine and $p<0.05$ for haloperidol).

142948A dose effect or interaction between the two factors (Figure 5). Post hoc analysis showed that all APDs significantly increased the number of Fos positive neurons in the lateral septum $(p<0.001$ for olanzapine and clozapine and $p=0.04$ for haloperidol). Olanzapine and clozapineinduced Fos expression was significantly higher $(p<0.001)$ than haloperidol-induced Fos expression in this brain region. The NTR antagonist had no significant effects in vehicle or APD treated animals.

\section{Effects of SR 142948A on APD-Induced Catalepsy}

Wood block test. Two-way ANOVA of the area under the curve of the descent latencies over all four time points revealed a significant APD effect $\left(p<0.001, \mathrm{~F}_{3,50}=24.9\right)$, but no significant effect of SR142948A $(p=0.12)$ or interaction between the two factors $(p=0.41)$. Post hoc analysis showed that only haloperidol $(p<0.001)$ but not clozapine, olanzapine, or SR142948A led to a significant increase in descent latency (catalepsy) compared to vehicle treated animals. The NT receptor antagonist had no significant effect on haloperidol- or clozapine-induced catalepsy, but significantly increased descent latency following olanzapine administration $(p<0.05)$, so that in the SR142948A/ olanzapine group catalepsy was significantly increased compared to vehicle treated animals $(p=0.01)$ (see Figure $6 a-d)$. When the four time points were analyzed separately, the SR142948A/olanzapine groups had significantly higher catalepsy scores $(p<0.05)$ than vehicle treated animals at the 15 and $30 \mathrm{~min}$ time-point while olanzapine treated animals did not differ from vehicle treated animals at any time point. 
Bar test. Two-way ANOVA of the area under the curve of the descent latencies over all four time points revealed a significant APD effect $\left(p<0.001, F_{3,55}=89.02\right)$, but no significant effect of SR142948A $(p=0.71)$ or interaction
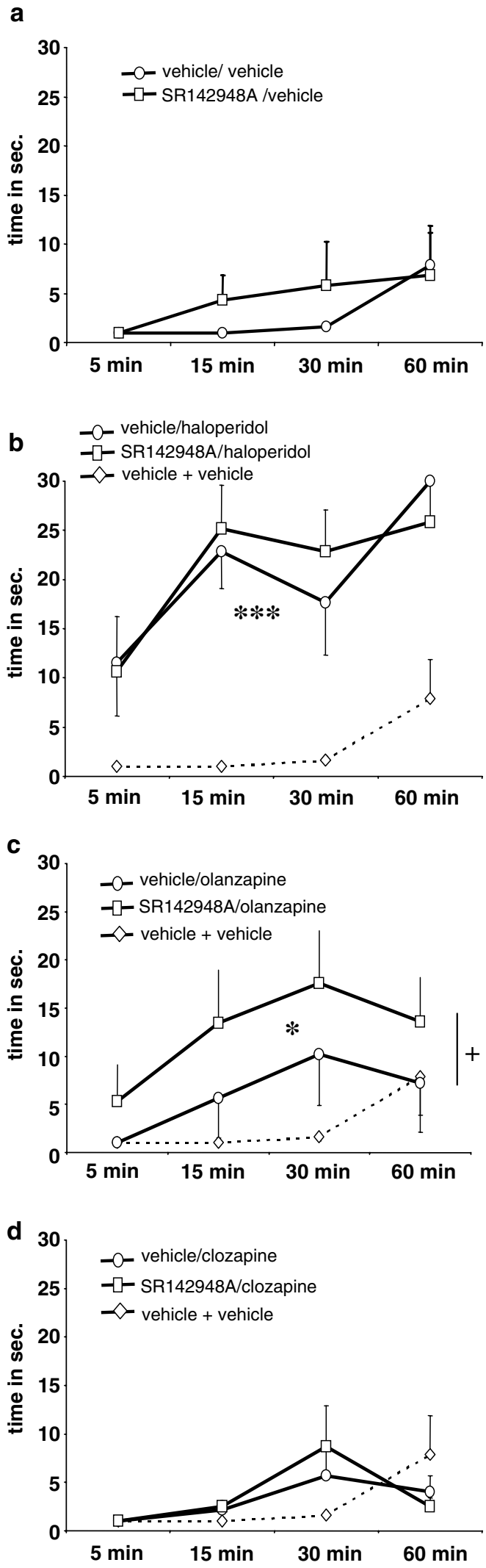

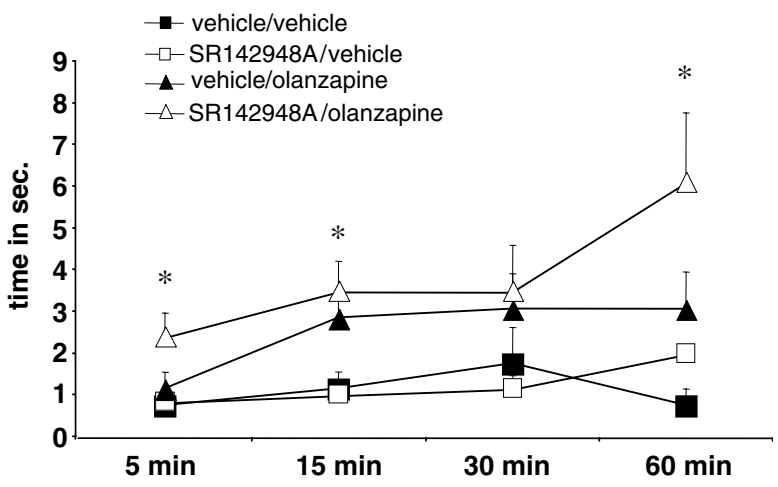

Figure 7 Effects of the neurotensin receptor antagonist SR I42948A on olanzapine-induced catalepsy in the bar test. SR I42948A (0 or $100 \mu \mathrm{g} /$ kg i.p.) was administered I h before administration of olanzapine. $* p<0.05$ for difference from vehicle/vehicle group at each time point.

between the two factors $(p=0.48)$. Post hoc analysis showed that only haloperidol $(p<0.001)$ but not clozapine, olanzapine, or SR 142948A led to a significant increase in descent latency (catalepsy) compared to vehicle treated animals. The NT receptor antagonist had no significant effect on haloperidol- or clozapine-induced catalepsy, but showed a trend to increase descent latency following olanzapine administration $(p<0.1)$. When the four time points were analyzed separately, the SR142948A/olanzapine groups had significantly higher catalepsy scores $(p<0.05)$ than vehicle treated animals at the 5, 15, and 60 min time-point while olanzapine treated animals did not differ from vehicle treated animals at any time point (see Figure 7).

\section{DISCUSSION}

Our results confirm and extend the previous findings of Fadel et al (2001) and Dobner et al (2001) concerning the involvement of NT neurotransmission in APD-induced Fos expression in the $\mathrm{CPu}$. We did not, however, observe any common effects of the NT receptor antagonist on APDinduced Fos-expression in limbic brain regions. Disruption of NT neurotransmission using the NT receptor antagonist SR 142948A changed the regional pattern of APD-induced Fos expression for the tested APDs, but no unitary effect was observed, which is in contrast to the effects of the NT receptor antagonist on APD-induced effects in sensorimotor gating (Binder et al, 2001a).

In agreement with the findings reported for SR 48692, pretreatment with SR 142948A reduced haloperidol-induced Fos expression in the dorsolateral $\mathrm{CPu}$ (Fadel et al, 2001). SR 48692 is a NT receptor antagonist that is relatively selective for $\mathrm{NT}_{1}$, the receptor subtype that has so far been

Figure 6 Effects of the neurotensin receptor antagonist SR I42948A on antipsychotic drug-induced catalepsy in the wood block test. SR I42948A (0 or $100 \mu \mathrm{g} / \mathrm{kg}$ i.p.) was administered I h before administration of antipsychotic drug (a: vehicle, b: haloperidol, c: olanzapine, d: clozapine). Stars indicate that both treatment groups are significantly different from vehicle/vehicle. $* p<0.05$ compared to vehicle/vehicle. $* * * * 0<0.00$ I compared to vehicle/ vehicle. $+p<0.05$ SRI 42948A/olanzapine compared to vehicle/olanzapine. 
implicated in the pre- and postsynaptic effects of NT on the mesolimbic and nigrostriatal dopamine system (Gully et al, 1993; Tyler et al, 1998; Vincent et al, 1999). $\mathrm{NT}_{2}$, another Gprotein coupled NT receptor, is also widely expressed in the brain including dopaminergic nuclei (the ventral tegmental area and substantia nigra) and the NAcc and its activation could be involved in APD-induced Fos expression in some brain regions (Walker et al, 1998). SR 142948A has equal affinity for $\mathrm{NT}_{1}$ and $\mathrm{NT}_{2}$ in the nanomolar range and several studies indicate that SR 48692 and SR 142948A may also distinguish between different pharmacological NT receptor subtypes (Gully et al, 1997; Vincent et al, 1999). We chose to use SR 142948A, as it cannot be ruled out that effects of NT at $\mathrm{NT}_{2}$ may also contribute to APD-induced Fos expression. The results of this study are similar to those reported for SR 48692 indicating that disruption of $\mathrm{NT}_{1}$ receptor mediated transmission is crucial for the observed reduction in haloperidol-induced Fos expression in the CPU and that there is no additional contribution of $\mathrm{NT}_{2}$. The documented enhanced NT release in this brain region following haloperidol administration (Huang and Hanson, 1997; Radke et al, 1998) may thus partially mediate haloperidolinduced Fos expression, by direct activation of NT1 in striatal neurons (Ehlers et al, 1998; Lambert et al, 1996; Portier et al, 1998) or by acting on $\mathrm{NT}_{1}$ receptors located on glutamatergic corticostriatal projections or dopaminergic projections (Boudin et al, 1996; Goedert et al, 1984).

Pretreatment with the NTR antagonist SR 142948A increased Fos expression in the dorsomedial and dorsolateral $\mathrm{CPu}$ in combination with olanzapine, but had no effect by itself in these brain regions. Olanzapine increases NT peptide concentrations and NT release in the NAcc but not the CPu (Kinkead et al, 1997; Radke et al, 1998). The effects of the NTR antagonist on olanzapine-induced Fos expression may therefore be mediated by antagonizing basal NT transmission in the $\mathrm{CPu}$. Several groups have reported detectable, albeit low, basal NT release in this brain region (Radke et al, 1998; Wagstaff et al, 1996).

The NT receptor antagonist had no effect on clozapineinduced Fos expression in these brain regions. Disrupting NT neurotransmission thus has no common effect on APDinduced Fos expression in the dorsolateral $\mathrm{CPu}$. This underlines the fact that NT serves as neuromodulator and can exert opposite effects depending on the level of activity of other neurotransmitter systems.

Both increased Fos expression and NT neurotransmission in the dorsolateral striatum have been linked to the EPSE liability of APDs (Adams et al, 1997; Decker et al, 1995; Shibata et al, 1987; Ward and Dorsa, 1999). NT receptor antagonism and a genetically disrupted NT neurotransmission both decrease haloperidol-induced Fos expression in the dorsolateral $\mathrm{CPu}$ but do not have an effect on haloperidol-induced catalepsy (Dobner et al, 2001). The fact that developmental adaptations in transgenic mice may be responsible for that discrepancy can be ruled out as we observed identical results with the NT receptor antagonist in wild-type animals.

We also examined the effects of disrupting NT neurotransmission on motor effects of the atypical APDs clozapine and olanzapine. Although clozapine does not induce catalepsy up to very high doses $(100 \mathrm{mg} / \mathrm{kg})$, olanzapine can induce catalepsy at doses over $10 \mathrm{mg} / \mathrm{kg}$
(Ellenbroek, 2000). Such doses of olanzapine are several fold higher than those needed for behavioral effects thought to reflect therapeutic efficacy, such as the prepulse inhibition of the acoustic startle reflex or latent inhibition (Ellenbroek, 2000). We observed that the NT receptor antagonist did not produce any effect on descent latency either by itself or in combination with clozapine. Pretreatment with SR 142948A, however, induced catalepsy in rats that were administered $5.0 \mathrm{mg} / \mathrm{kg}$ olanzapine, a dose that did not induce catalepsy by itself. This observation was made when using the woodblock as well as the bar test to measure catalepsy (see Figures $6 c$ and 7). The enhancement of catalepsy was paralleled by an increase in Fos expression in the dorsomedial and dorsolateral $\mathrm{CPu}$. This molecular and behavioral concordance is contrary to the findings with haloperidol. As suggested above, the effects of the NT receptor antagonist on both olanzapine-induced Fos expression and catalepsy may stem from counteracting the neuromodulator activity of basal NT release in the $\mathrm{CPu}$. Basal NT release may therefore be necessary for the favorable motor side effect profile of some atypical APDs.

Pretreatment with the NT receptor antagonist did not alter APD-induced Fos expression for any of the investigated compounds in the limbic brain regions, the NAcc, the PFC, or the LS. The common induction of Fos expression by APDs in the NAcc, CPu or PFC has been attributed to their common therapeutic or side effect profile. For a neurotransmitter system to be involved in a specific therapeutic aspect of APDs, one would expect to observe a consistent change in APD-induced Fos expression pattern following its disruption. In our experiments we did not observe any consistent influence of SR 142948A pretreatment on APDinduced Fos expression. In contrast, there is evidence for a common role of NT neurotransmission in the effects of both a typical and an atypical APD on behavioral tests for antipsychotic activity. SR 142948A was able to prevent haloperidol- and quetiapine-induced restoration of prepulse inhibition of the acoustic startle reflex in isolation reared rats (Binder et al, 2001a), and this is most likely mediated by the antagonism of NT neurotransmission in the NAcc (Feifel et al, 1997). This difference could be explained by the divergence in APD doses inducing sensorimotor gating effects (up to 20 times less) compared to those inducing Fos-expression. Nonetheless, our findings challenge the view that manipulating APD-induced Fos expression in the NAcc provides insight into the neurotransmitter systems involved in the therapeutic efficacy of APDs. Caution may thus be warranted in using regionally specific APD-induced Fos expression as a screening tool for antipsychotic activity.

\section{ACKNOWLEDGEMENTS}

Supported by grants NIH MH-39415 and from the Eli Lilly Company.

\section{REFERENCES}

Adams MR, Brandon EP, Chartoff EH, Idzerda RL, Dorsa DM, McKnight GS (1997). Loss of haloperidol induced gene expression and catalepsy in protein kinase A-deficient mice. Proc Natl Acad Sci USA 94: 12157-12161. 
Binder EB, Kinkead B, Owens MJ, Kilts CD, Nemeroff CB (2001a). Enhanced neurotensin neurotransmission is involved in the clinically relevant behavioral effects of antipsychotic drugs: evidence from animal models of sensorimotor gating. J Neurosci 21: 601-608.

Binder EB, Kinkead B, Owens MJ, Nemeroff CB (2001b). The role of neurotensin in the pathophysiology of schizophrenia and the mechanism of action of antipsychotic drugs. Biol Psychiat 50: 856-872.

Boudin H, Pélaprat D, Rostène W, Beaudet A (1996). Cellular distribution of neurotensin receptors in rat brain: immunohistochemical study using an antipeptide antibody against the cloned high affinity receptor. J Comp Neurol 373: 76-89.

Braff DL, Geyer MA (1990). Sensorimotor gating and schizophrenia. Human and animal model studies. Arch Gen Psychiat 47: 181-188.

Cohen BM, Wan W (1996). The thalamus as a site of action of antipsychotic drugs. Am J Psychiat 153: 104-106.

Decker KP, Roy-Byrne PP, Merchant KM (1995). Effect of muscimol on haloperidol-induced alteration of neurotensin gene expression in the striatum and nucleus accumbens in the rat. Brain Res 691: 9-17.

Deutch AY (1994). Identification of the neural systems subserving the actions of clozapine: clues from immediate-early gene expression. J Clin Psychiat 55: 37-42.

Deutch AY, Lee MC, Iadarola MJ (1992). Regionally specific events of atypical antipsychotic drugs on striatal Fos expression: the nucleus accumbens shell as a locus of antipsychotic action. $\mathrm{Mol}$ Cell Neurosci 3: 332-341.

Deutch AY, Ongur D, Duman RS (1995). Antipsychotic drugs induce Fos protein in the thalamic paraventricular nucleus: a novel locus of antipsychotic drug action. Neuroscience 66: 337-346.

Dobner PR, Fadel J, Deitmeyer N, Carraway RE, Deutch AY (2001). Neurotensin-deficient mice show altered responses to antipsychotic drugs. PNAS 98: 8048-8053.

Ehlers II RA, Bonnor RM, Wang X, Hellmich MR, Evers BM (1998). Signal transduction mechanisms in neurotensinmediated cellular regulation. Surgery 124: 239-246.

Ellenbroek BA (2000). The effect of olanzapine in animal models predictive of antipsychotic activity. In: Tran PV, Bymaster FP, Tye N, Herrera JM, Breier A, Tollefson GD (eds). Olanzapine (Zyprexa): A Novel Antipsychotic. Lippincott Williams \& Wilkins Healthcare: Philadelphia. pp 57-68.

Ellenbroek BA, Peeters BW, Honig WM, Cools AR (1987). The paw test: a behavioural paradigm for differentiating between classical and atypical neuroleptic drugs. Psychopharmacology 93: 343-348.

Fadel J, Dobner PR, Deutch AY (2001). The neurotensin antagonist SR 48692 attenuates haloperidol-induced striatal Fos expression in the rat. Neurosci Lett 303: 17-20.

Feifel D, Minor KL, Dulawa S, Swerdlow NR (1997). The effects of intra-accumbens neurotensin on sensorimotor gating. Brain Res 760: $80-84$.

Fibiger HC (1994). Neuroanatomical targets of neuroleptic drugs as revealed by Fos immunochemistry. J Clin Psychiat 55: 33-36.

Goedert M, Pittaway K, Emson PC (1984). Neurotensin receptors in the rat striatum: lesion studies. Brain Res 299: 164-168.

Gully D, Canton M, Boigegrain R, Jeanjean F, Molimard JC, Poncelet $\mathrm{M}$ et al (1993). Biochemical and pharmacological profile of a potent and selective nonpeptide antagonist of the neurotensin receptor. Proc Natl Acad Sci USA 90: 65-69.

Gully D, Labeeuw B, Boigegrain R, Oury-Donat F, Bachy A, Poncelet $M$ et al (1997). Biochemical and pharmacological activities of SR 142948A, a new potent neurotensin receptor antagonist. J Pharmacol Exp Ther 280: 802-812.

Huang W, Hanson GR (1997). Differential effect of haloperidol on release of neurotensin in extrapyramidal and limbic systems. Eur J Pharmacol 332: 15-21.

Kilts CD, Anderson CM, Bissette G, Ely TD, Nemeroff CB (1988). Differential effects of antipsychotic drugs on the neurotensin concentration of discrete rat brain nuclei. Biochem Pharmacol 37: 1547-1554.

Kinkead B, Binder EB, Nemeroff CB (1999). Does neurotensin mediate the effects of antipsychotic drugs? Biol Psychiat 46: 340-351.

Kinkead B, Owens MJ, Nemeroff CB (1997). The effects of subchronic antipsychotic drug administration on neurotensin concentrations in the rat brain. Soc Neurosci Abstr 23: 653.11.

Kinkead B, Shahid S, Owens MJ, Nemeroff CB (2000). Effects of acute and subchronic administration of typical and atypical antipsychotic drugs on the neurotensin system of the rat brain. J Pharmacol Exp Therap 295: 67-73.

Lambert PD, Ely TD, Gross RE, Kilts CD (1996). Neurotensin induces Fos and Zif268 expression in limbic nuclei of the rat brain. Neuroscience 75: 1141-1151.

Merchant KM, Dobie DJ, Dorsa DM (1992). Expression of the proneurotensin gene in the rat brain and its regulation by antipsychotic drugs. Ann NY Acad Sci 668: 54-69.

Merchant KM, Figur LM, Evans DL (1996). Induction of c-fos mRNA in rat medial prefrontal cortex by antipsychotic drugs: role of dopamine D2 and D3 receptors. Cerebr Cortex 6: 561-570.

Paxinos G, Watson C (1986). The Rat Brain in Stereotaxic Coordinates. Academic: San Diego.

Portier M, Combes T, Gully D, Maffrand JP, Casellas P (1998). Neurotensin type 1 receptor-mediated activation of krox 24 , c-fos and Elk-1: preventing effect of the neurotensin antagonists SR 48692 and SR 142948. FEBS Lett 432: 88-93.

Radke JM, MacLennan AJ, Beinfeld MC, Bissette G, Nemeroff CB, Vincent SR et al (1989). Effects of short- and long-term haloperidol administration and withdrawal on regional brain cholecystokinin and neurotensin concentrations in the rat. Brain Res 480: 178-183.

Radke JM, Owens MJ, Ritchie JC, Nemeroff CB (1998). Atypical antipsychotic drugs selectively increase neurotensin efflux in dopamine terminal regions. Proc Natl Acad Sci USA 95: 1146211464.

Robertson GS, Fibiger HC (1992). Neuroleptics increase c-fos expression in the forebrain: contrasting effects of haloperidol and clozapine. Neuroscience 46: 315-328.

Robertson GS, Fibiger HC (1996). Effects of olanzapine on regional C-Fos expression in rat forebrain. Neuropsychopharmacology 14: 105-110.

Sebens JB, Koch T, Ter Horst GJ, Korf J (1995). Differential Fosprotein induction in rat forebrain regions after acute and longterm haloperidol and clozapine treatment. Eur J Pharmacol 273: $175-182$.

Shibata K, Yamada K, Furukawa T (1987). Possible neuronal mechanisms involved in neurotensin-induced catalepsy in mice. Psychopharmacology 91: 288-292.

Swerdlow NR, Geyer MA (1998). Using an animal model of deficient sensorimotor gating to study the pathophysiology and new treatments of schizophrenia. Schizophrenia Bull 24: 285-301.

Tyler B, Cusack B, Douglas C, Souder T, Richelson E (1998). Evidence for additional neurotensin receptor subtypes: neurotensin analogs that distinguish between neurotensin-mediated hypothermia and antinociception. Brain Res 792: 246-252.

Vincent JP, Mazella J, Kitabgi P (1999). Neurotensin and neurotensin receptors. Trends Pharmacol Sci 20: 302-309.

Wagstaff JD, Gibb JW, Hanson GR (1996). Dopamine D2-receptors regulate neurotensin release from nucleus accumbens and striatum as measured by in vivo microdialysis. Brain Res 721: 196-203.

Walker N, Lépée-Lorgeoux I, Fournier J, Betancur C, Rostene W, Ferrara $\mathrm{P}$ et al (1998). Tissue distribution and cellular localization of the levocabastine-sensitive neurotensin receptor mRNA in adult rat brain. Mol Brain Res 57: 193-200.

Ward RP, Dorsa DM (1999). Molecular and behavioral effects mediated by Gs-coupled adenosine A2a, but not serotonin 5-Ht4 or 5-Ht6 receptors following antipsychotic administration. Neuroscience 89: 927-938. 